\title{
The ceramic age: a gloss on depth
}

\author{
Alan Read \\ Department of English \\ King's College London \\ alan.read@kcl.ac.uk $\quad$ http://www.performancefoundation.orq.uk
}

\begin{abstract}
The Mesopotamian invention of suspended narratives in mineral pigment and glaze produced in the fifteen thousand year old 'new technology' of the ceramic tile sets the scene for my talk for EVA 2010 (and this published paper which is intended to act as a prologue to that talk). It was this invention, a mass-produced media technology with the limit of a prototype glass screen that allowed commentators to distinguish between the repetitious, the mimetic and the bespoke for the first time.
\end{abstract}

The ceramic tile had the added dimension of a porous, Silesian sandy surface to its rear-side that promised some sort of permeability with the outside world with which it interfaced. So in the ceramictile we have the classic bonding of a surface of impermeable aesthetics founded on a promise of interactivity with the environment within which the work takes its place. The technology operating here is not dissimilar in its logics to that of a genealogy of subsequent pretenders to the fruits of a tension between surface and immersion in a 'world': from viscous oil painting to video installation, from television to Nintendo.

It would be the holy grail of interactivity to be in a position to announce this moment as the end of the ceramic age. Immersive technologies motored by digital apparatuses promise virtual environments that might, just might, provide us with the much-desired figure of a 'point of entry'. The recalcitrance of the veneered surface of the ceramic model would thus be finally consigned to history. This paper will sketch out some reasons why my own field of theatre and performance might have some reservations as to such a voluntaristic claim, and why looking 'around the back' of the image machine can still bear some fruit in the age of the apparatus.

\section{INTRODUCTION}

Great progress has been made $[\ldots]$ in the manufacture of pottery. Surely this has something to do with our national character. We do not dislike everything that shines, but we do prefer a pensive luster to a shallow brilliance [...] (Tanizaki, 2001)

I will start anecdotally, close to home, a couple of years ago at the time of writing, in an unyielding, hard place. I will then propose a 40,000-year jump to the 'stone age' to explore how such aesthetic impermeability came about, and then come back towards the permeable promise of today's programmed practices via the 'ceramic age' of my title. I hope that is clear as a time line. These notes are intended as a prologue for my talk at EVA 2010, which will attempt to distinguish between the ceramic age and an age of apparatus that, since the advent of photography, has revolutionised a human's capacity to play while transforming the stakes of such practices. A specialist in performance might not be wholly irrelevant nor deemed necessarily inadequate to asking what this playful capacity of apparatuses might imply and how they may differ from the dense promise of interactivity that has been with us for 15,000 years since the first pigment was suspended in a glassy veneer on a sandy surface.

To the extent that these notes will be read post EVA 2010 they simply mark the gap (my own, not yours) that existed at the time of their writing between an aesthetic sensibility of 'scanning' once founded on the reading of an impermeable screen surface bonded to a promise of interactivity (the ceramic age) and a numerical sensibility of 'programming' that emerged through the realisation of the true vocation of an 'age of the apparatus', needing always to be prepared for something, indeed defined by the anxiety of their readiness to act. That these notes end with a title: 'The Age of Apparatus: Preparation for Practice' is indication that what apparently 'follows' the ceramic age, despite being a century 
and a half in the making, is by no means transparent and remains to be worked through into its second century (as well as with the participants at EVA 2010 for whom a tabula rasa has been left available for any notes that might critically articulate this gap).

What we can surmise (with the philosopher Vilem Flusser, 2000, p. 25) at this stage is that apparatuses do not change the world but 'change the meaning of the world'. They are not tools but playthings and in reality are indistinguishable from those who operate within and around them, as distinct to operate them (the dynamic that might once have been the functional relationship between a technology of previous ages and a human living through that era). This 'functionary', as Vilem Flusser would have it, controls the exterior of the apparatus for sure, but, since the camera, they have also been controlled by it 'thanks to the impenetrability of the interior' (Flusser, 2000, p. 28). To all intents and purposes (and dire warnings as to the consequences of broaching the membrane at the back of the machine testify to this discretion) this state of play has not changed since the mid- $19^{\text {th }}$ century except with one important caveat that provides the motor for gatherings where electronic/digital sensibilities meet art's capacities (including the various constellations of EVA over a number of years).

In this age a functionary of an apparatus is one who may, still, have no competence in the internal workings of an apparatus but continuously seeks such a thing through a willingness to explore the potential of the apparatus through play. We are in this sense all artful amateurs now, and hence the democratic promise of the age. Everything beyond the operative and the functional in each of these apparatuses is down to their willingness and ability to recognise that the functionary is being released into play. The question for Vilem Flusser is not who owns the apparatus, (as might have been relevant in the machine age of the industrial revolution) but rather who develops the program? The 'hard core' of the stone age and the 'medium core' of the ceramic age has been replaced by the 'soft core' of the age of the apparatus where the appliance itself is next to free while the software becomes more and more expensive, more and more regulated. It is this promise of enhanced performance over the right to, and rite of, programming that generates the necessary dynamic of optimism in a world once characterised by its technological melancholia.

But before I get carried away with the possibilities, some prehistoric reflections on the limits to previous models of interactive promise followed by a short history lesson to allow for some post-historical propositions in the future (past) that is EVA 2010.

\section{THE STONE AGE: A BRUSH WITH SURFACE}

Where was I in 2007 that started me thinking about this? At the Institute of Contemporary Arts in London. Hermione, my younger daughter then 8 years old, was booked into what was described as a drawing workshop. I took this to be a salve to the local Westminster council that the ICA did serious outreach work and took the chance to sign up, along with other middle class parents, to some cheap crayons and paper subsidised by the central-London dispossessed. When we arrived we were briefed by the ICA staff, and it became apparent that this community workshop was not quite what it appeared. Hermione was with her friends Iona and Isabel, and alongside 20 other children aged between 7 and 9 . They were asked by a staff member convening the workshop an apparently straightforward question: 'What is this place?' A bright spark said 'a museum' to which the staff member replied 'yes, an art gallery'. I almost interjected that this might be something of a moot distinction but saw Hermione giving me the warning eye, so I didn't. 'And do you make art?' a staff member asked? 'Yes' said the children unanimously. 'And are you artists?' 'No' said most of the children. 'Would you like to be artists?' said the grown up. 'Yes' the children cried (and our inner parenting-artist-selves concurred from the sidelines).

'Right!' they said. 'Before you can get on with your drawing workshop we would like you to split into two groups. One group will be asked to go downstairs to the gallery space and there, without objects of any kind, you will be asked to play. Who would like to say something?' So Hermione put up her hand. 'Where's the toilet?' she asked. 'No', said the staff member, 'I mean say something in the gallery?' 'Well if I can go to the toilet first, I am happy to say something later' said Hermione. 'Right!' said the grown up, 'you will step out of whatever game you are playing at the time, and go up to and say the following line to anyone who comes into the gallery during today: "Hello, my name is, whatever your name is, and I would like to call the work, This Success". Or you could say if you feel otherwise: "Hello, My name is, whatever your name is, and I would like to call the work This Failure".' 'My name's Hermione', said Hermione, with an economy of language that I mentally jotted down as being inherited from her mother's side.

Despite the fact that this drawing workshop had never been named it quickly became apparent to me, 
from this instruction, as a one-time insider now masquerading as an outsider to the workings of this institution, that my daughter was being briefed to become part, a speaking part no less, part of the distinguished performance artist Tino Sehgal's work, Tino Sehgal 2007, the third in his trilogy for the ICA over three years. I will leave it to Nicholas Bourriaud the author who has built a career on analysing this kind of 'relational aesthetic' work to mine this repertoire for further meaning, but I was struck by something precisely material about the success and failure of this work. And it is that materialism that I hope I hint at in my title: The Ceramic Age, though here, in the ICA in 2007 (and to date no different) the solid state physics I am interested in are initially more comprehensible through the figure of the 'stone age'.

The event was being conducted in an absolutely neutral room, albeit obviously an architecturally formed exhibition space, with a white door covering the normally cherished escape route via the front desk. There was an intense display of play at work when the parents returned, with various degrees of faux theatricality and apparently innocent goodwillbrushing of girl's hair (still no objects) and clapping games. But amidst all this to-ing and fro-ing what was inescapable was the floor, which was way too hard for its own good, or indeed for the children playing on it. At one point a boy fell and hit his head quite hard in that slightly sickening thud-like way that adults just don't do. It was pure stone, laid by the great modernist Jane Drew in 1967, shiny and reflective of the action but unforgiving, the most utterly trapdoor less floor that you could imagine. It was a quarried out, screen surface, but one so dense as not to appear to have any light of its own, nor offering any means nor hope to broach its utter impermeability.

And this struck me as interesting (and does again more forcefully now in the context of an event such as EVA) in which the rhetorics of immersive staging might presume that a certain hollowness is what supports the conventions of stage action. This is the kind of volume that European theatre companies such as Backtruppen have used to great effect beneath the audience bleechers in their work. But here, in the hollowed out, reverse figure to that solidstate ICA floor there is an eminent tradition of exploration that links the inner-stage to the potential for revolutionary acts. The Situationists said in 1968 something that could be loosely translated as: 'Beneath the cobblestones the beach' a sentiment that echoes the romantic volumetric underbelly of the urban stage. In Lindsay Anderson's 'anatomy of a public school film' If, this mysterious, hollow substage volume is the very seat of resistance. Beneath the school stage is a hidden world within which this kind of recovery of imagination and history, not to mention the relics of the formaldehyded anthropological machine, can be brought to light and examined. And it is from here that the revolution against the school authorities is staged in the final part of the film Crusaders.

But let us return from such hollow revolutionary voluntarism, the pseudo activism of the 1960s counter culture, to the harder material recalcitrance of the evacuated 'noughties' ICA floor. They announced the end of the Tino Sehgal piece, and I was glad that I had taken the chance to read Nicholas Bourriaud's Relational Aesthetics in the ICA café during the afternoon, above the action of my own child who I was not able to witness in case I inhibited her pre-Lapsarian play. For in that work I was able to establish that what Tino Sehgal is up to, alongside his artist contemporaries: Philippe Pareno, Vanessa Beecroft, Maurizio Cattelan and Carsten Holler, is to do with what Bourriard calls: 'interactive, user-friendly and relational concepts'. He asks through exploring this work: 'is it still possible to generate relationships with the world' (Bourriaud, 2002). His ideas of conviviality and encounter sound very much like the kind of soft performative inherent to community engagements at the fringe of theatre practice since Eisenstein occupied a factory for an event in the 1920s, and Rousseau asked some years before what the public might be doing when they grouped at the village maypole.

So my first materialist model reminds me to take more notice of the ground on which action occurs, not necessarily to dig into it in a hermeneutic enterprise, the kind of archaeological model so brilliantly conducted by Mike Pearson in his work Theatre/Archaeology, but to account for it in my study of performances and the relationship between such rhetorics and the mechanisms of other media machines (Pearson, 2000). The history of paradigm, disciplinary or knowledge formation, is, as any Archaeology of Knowledge shows, one of concealments as much as revelations, an archaeology itself is a process of disinterring those things about epistemology that have become hidden in time. But it has been the common currency of all such strategies to conceal things, for objects have always had a recalcitrance about them, from the chemistry laboratory to the physics chamber, that resist our humanist expectations. Things object to our subjecting them to experiment. The roots of the word laboratory, a word first used in English in 1608 around the time that Shakespeare was completing The Tempest, the 'labour of oratory', forcing things to speak, is a reminder of the violence inherent to all demonstrations of discoveries. So in its concealing of 
things performance studies is in good company. It is no slight to a discipline to admit its propensity to hide things, if only in order to reveal them dramatically with the magician's exclamation: 'lo and behold'. Look and behold indeed, for it is magic that curiously binds the performances I am speaking about to the apparatuses that I will come to in my EVA 2010 talk.

\section{THE CERAMIC AGE: A GLOSS ON DEPTH}

There are no records of the earliest performances that would have been studied, they are literally prehistoric, but it is logical to assume that once the twodimensional readings of 'media studies' had developed the three dimensions of 'live performance' would have been recognised, commented on and critically addressed for their contrasting depth and presence. To fancifully extend Philip Auslander's logic in his book Liveness that it was only at the inception of recorded television that the 'live' became identifiable as a discreet and distinct activity, it was in my view only at the inception of the first mediascreen that performance could be separated out and examined for its difference (Auslander, 1997).

The screen I am talking about here, contrary to Auslander and Nicholas Bourriaud, who both presume the screen to have something to do with either televisions or computer terminals, was not the relatively recent invention of the television. But nor was it as old as the Upper-Palaeolithic cave interior at Lascaux, that Georges Bataille described as 'the cradle of humanity'. That chalked-on wall provided an early if under-illuminated prototype of the ability of human animals to picture their animal quarry, and then to figure themselves as laughing at them.

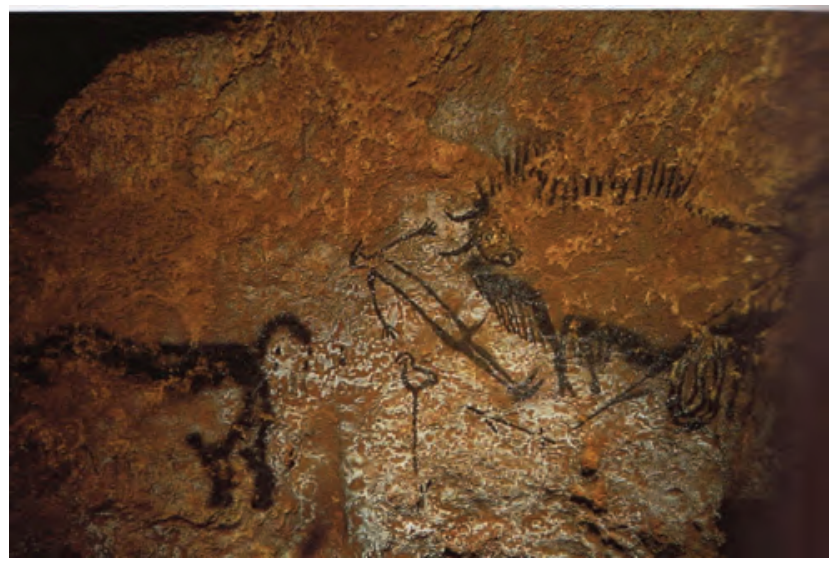

Figure 1: Lascaux Painting of 'Laughing' Man

The shame of the hunter, the only human being pictured in Lascaux, was thus the first pictorial relationship between animal and man. But this was a bespoke artistry, unique on each extraordinary occasion from Altamira to Peche Merle. The tactility of this pigment work, the intimate relationship between hand and surface, shared more with the performance of each hunting sortie than was able to throw that performative action, restored behaviour, from one kill to the next, into any relief. We have no writing of that relationship and can only speculate with Bataille that this prehistory is our history because it announces the subject, the I, it announces us. Bataille figures this entrance of the human in reassuringly theatrical terms:

\begin{abstract}
What we now conceive clearly is that the coming of humanity into the world was a drama in two acts. Better still: that the second act, in which the essential matters were decided, was preceded by a much vaguer and much longer act, which is comparable in its slowness and indecisive appearance to a period of incubation. (Bataille, 2005)
\end{abstract}

Rather, the screen I am interested in here, one that was documented and can therefore be discussed sensibly and with recourse to the evidence of history, that tells us something about the foundation of performance studies in relation to its mediatised siblings, was the more modern invention of suspended narratives in mineral colour and glaze produced in the fifteen thousand year old new technology of the ceramic tile. It was this invention, a mass-produced media technology with the limit of a prototype glass screen, that allowed commentators to distinguish between the repetitious, the mimetic and the bespoke for the first time.

The foundation of performance studies necessarily therefore comes 'after' the inception of a prototypical media studies. If you follow my reverse logic and timeline this peculiar inversion of our expectation occurred in Egypt in the fourth millennium BC. The Near East, with its tradition of baked or sun-dried brick, was the geographical cradle of architectural ceramics. From the year 4000 BC onwards Egyptians were producing tiles of a siliceous, sandy composition whose surface glaze was stained turquoise-blue with copper. These tiles were used to decorate the jambs of inner doorways in the Step Pyramid at Saqqara, south of Cairo. This blue, of course, was not arbitrary nor remotely abstract; for everyone who saw it the mineral would have been instantly recognisable as concerned with contemporary conceptions of divine power and eternal life. It was readable. It signified. These tiles were written about and commented upon by material savvy contemporaries for the first time, marking them out as the first 'media' to be studied. The earlier 
glazed tiles used by the Assyrians and Babylonians in Mesopotamia between the thirteenth and the fifth centuries BC seem to have passed without record or scriptural notice.

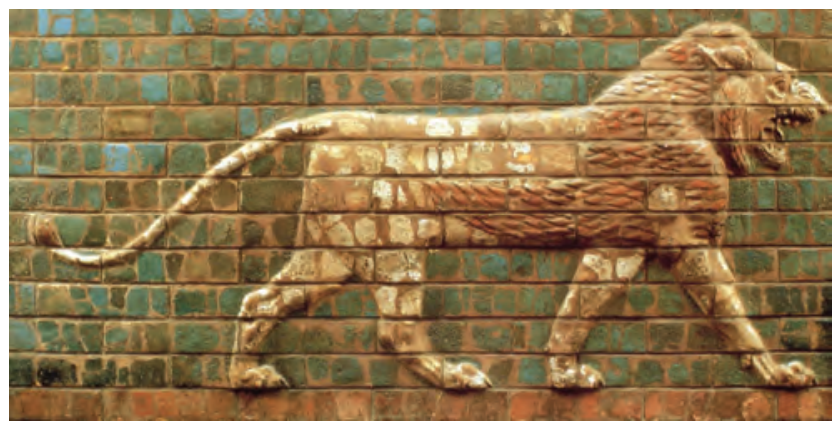

Figure 2: Nile Delta Temple

Within 2000 years, by 1180 BC in the Nile Delta at the Temple of Medinet Habu, the tiles are picturing captured slaves of different races, fabulous beasts, real animals and symbolic signs and ornaments. The age of narrative realism begins here, the veracity of the ceramic surface and its pictorial truth-to-life from now on set off against those things that happened in front of it, in true scale, in proximity to the spectator not abbreviated in size as demanded by the manufactured reduction of the mass-produced ceramic form.

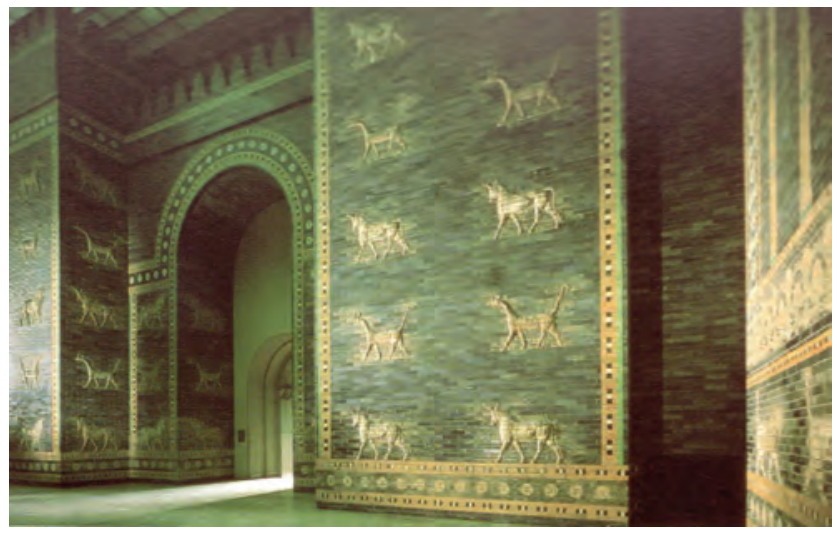

Figure 3: Architectural Tiles

The ceramic tile had the added dimension, critical for my argument here and any serious project that might grow from this idea in the context of EVA, of a porous surface to its rear-side that promised some sort of permeability with the outside world. At least it was a porosity that allowed the tile to breath with the surface to which it was attached, which in turn would commonly be a wall with an exterior aspect and therefore prey to the vicissitudes of changing levels of damp and drought. So in the ceramic tile we have the classic bonding of a surface of impermeable aesthetics founded on a promise of interactivity with the environment within which the work takes its place.

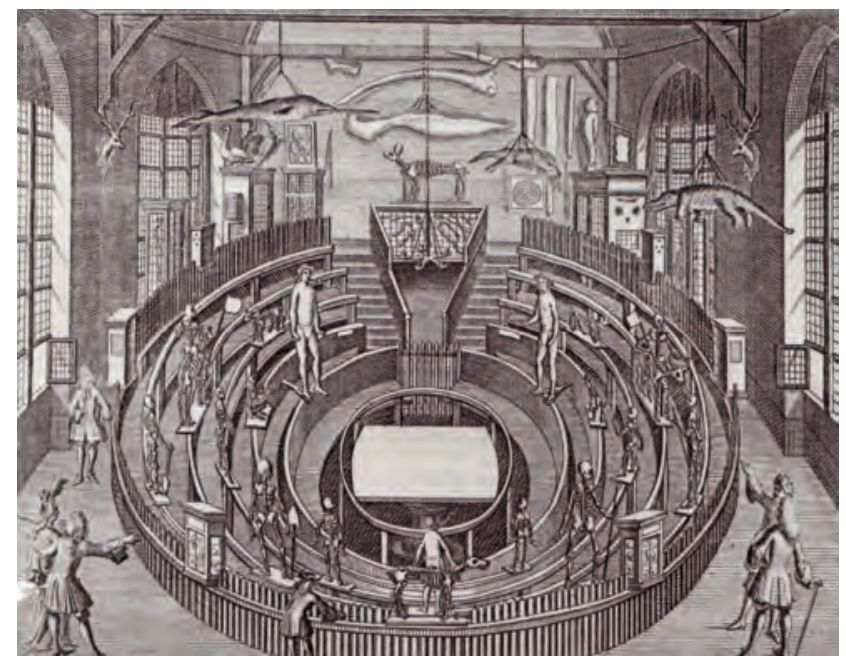

Figure 4: Operating Theatre Leiden

In my view there are still some, present company of EVA excepted, operating within the ceramic age, and not just in the operating theatres from de Waag in Amsterdam, Padua and Uppsala for whom anatomy theatres have become tiled icons of another era of spectatorial medicine.

The Young Vic Theatre in London recently reopened, still under the direction of the celebrated anthropologist David Lan.

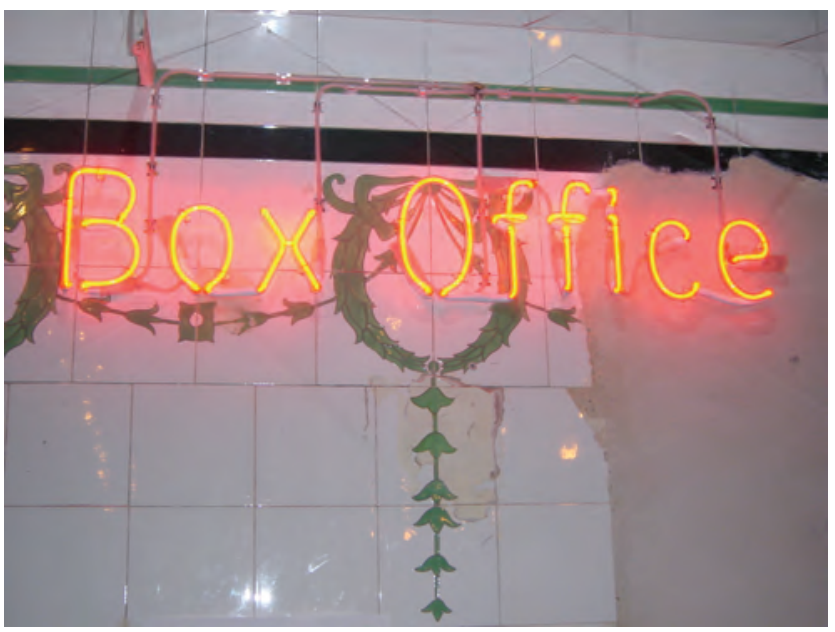

Figure 5: Young Vic Theatre Box Office Tiles

It could not have escaped David's anthropological eye that the only part of his theatre's wholly rebuilt interior left untouched by the architects Haworth Tompkins were the ceramic tiles that formed the wall 
of an Edwardian butcher's shop integrated into the building when originally built in the 1970s.

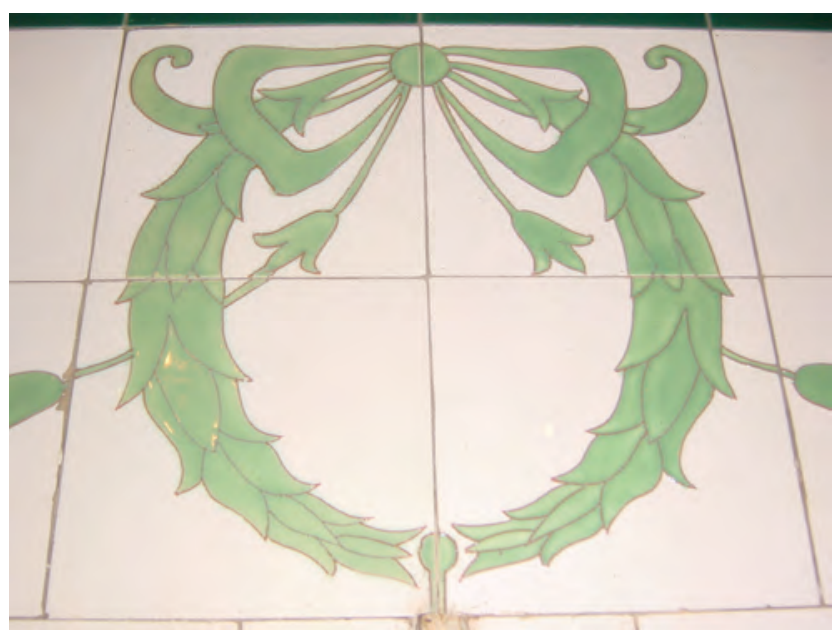

Figure 6: Butcher's Shop Tiles Young Vic

The tiles of the butcher's shop, like those earlier in the century, in more ominous surroundings across Eastern Europe, were of course well suited to the historical delusion that the bloody transition from the life of the live to the death of the dead could be wiped clean, a tabula-rasa for slaughtered animals at the end of each busy day in the aptly named street in Waterloo called The Cut.

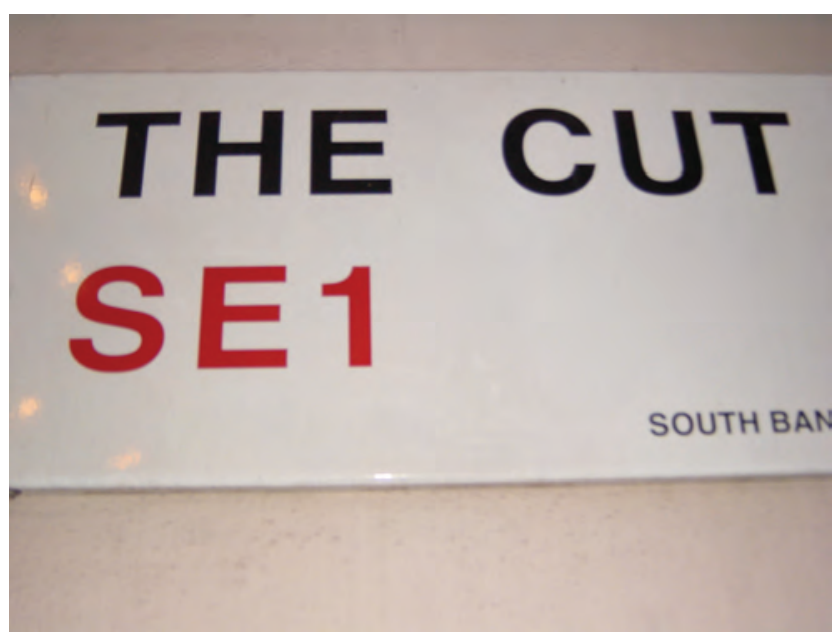

Figure 7: The Cut, Waterloo

There is little fundamental difference between the Nintendo DS Console that my daughters game with and the ceramic tile. They weigh about the same and their dimensions and opaque, milky hue are familiar. The light now emanates from within the screen but the narratives are similarly suspended close to the near-side of that screen. And of course their easy violences can be wiped clean with a single modest gesture across the surface. There is the tease of interactivity but this like almost all gaming is fantastically limited. It's a remedial activity rather like basket weaving would have been in a nineteenth century home for the insane. And the porosity to the world of the tile has been traded for a specious WiFi link to other gaming slabs but little outside engagement.

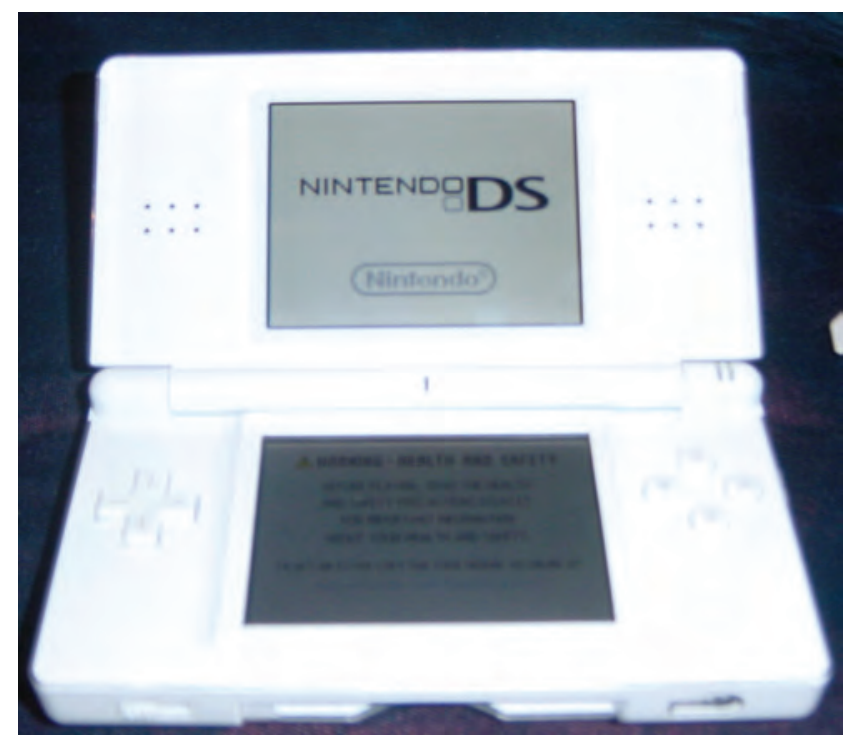

Figure 8: Nintendo DS

The technology at work here in the Nintendo, the techne or mechanics of revealing, has barely advanced on William de Morgan's Victorian tiles in my local pub The Tabard in west London, where narratives are continued across tiles in fluid temporal dynamics. And it falls well short of the heights of soaring Moroccan Mosques.

It would be the holy grail of interactivity to be in a position to announce this moment as the end of the ceramic age. Interactivity would provide us with the much-desired figure to consign the ceramic model to history. But there is little about the pre-photographic model of the theatre and its study from the Greek site on that disturbs. This is essentially a two-dimensional model with a lustrous yet impenetrable surface and a porous back. The theatre volume could be figured as leaky to the world but only from one side at a time and the proscenium arch reinforced the screen war in its face off with a front-seated audience, surfaces at work rather than volumes to be entered. It would be precisely this teasing promise of engagement through 'entry' that might be the excuse for adopting the paradigms I have done so far in this paper, paradigms that might act as means (in my EVA talk) to articulate some important distinctions between the interactive promise of technologies that replicate the 
order of the ceramic age, and those that genuinely confront the playful engagement of the age of apparatus.

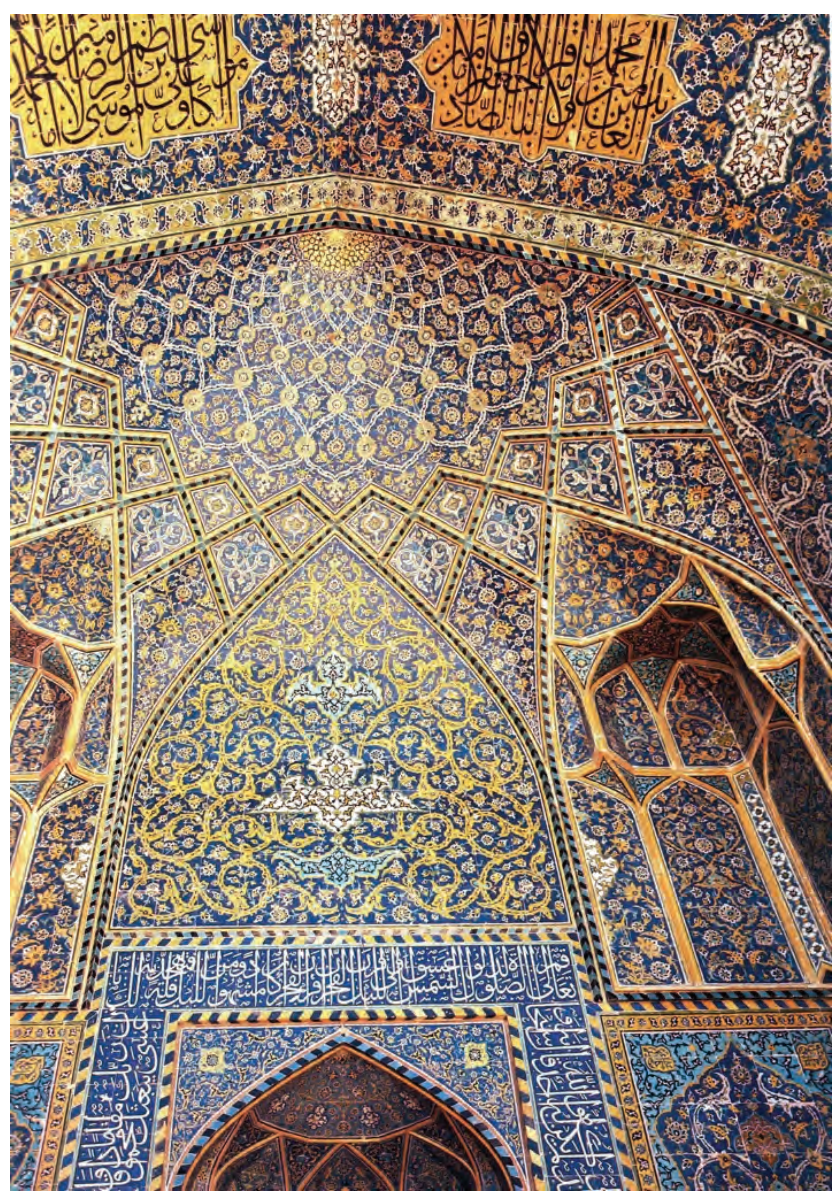

Figure 9: Shah Mosque Tiles

A century of theatrical experiment, from those Eisenstein directed immersive factory pieces in the early $20^{\text {th }}$ century through Jerzy Grotowski's paratheatricals to the current penchant for site-specific performance, has done little to alter the essential face-to-face encounter of the theatrical. And all this despite the heroic efforts of Jean- Francois Lyotard in his seminal work Libidinal Economy to figure performance as a complex, circulating Moebian Band of energetics confounding binary logic at every turn. 'Looking on' and wondering is the common theatrical mode of spectation irrespective of cultural origin.

This is not a problem for theatre! My proposal here is that it is precisely this repertoire of affects of adjustment that makes sitting in the dark watching the traffic of illuminated stages so interesting. This I would suggest is the defining 'immunisatory logic' of theatre, something that performance in all its guises has done little to destabilise, so powerful is its hold on us. And, in my view, this is the inherent anachronistic power of theatre that uses all its theatricality to unpick its own communitarian stupidity. Examples are myriad for they are modern theatre's history: Meyerhold's production of Earth Rampant in 1920s, to Pirandello's Six Characters in Search of an Author in the 1930s. Or indeed consider those European theatre auditoria that knowingly and judiciously unpicked their own distances of spectatorial arrangement: the Werkbund Theatre Cologne (1914), Walter Gropius' theatre for Erwin Piscator (1927) and of course Lissitsky's space for Meyerhold's production of I Want A Child (1934). These are Erika Fischer -Lichte's examples of what she signifies as the theatrical revolution of the $20^{\text {th }}$ century.

This is a problem for performance studies! It is my contention that it is this impermeability of the staged image, like the glazed tile, that has necessitated what Rene Girard would have described in Things Hidden Since the Foundation of the World as a certain scapegoating of the theatrical by performance studies as it chases the desire of all desires, involvement in a world that it seeks to cover while hiding the resistances it encounters to occupation. I would figure this as the recalcitrance of the field, which the discipline of performance study wishes to enter, a recalcitrance that one rarely sees quantified in the expansionist phase of disciplines. The recalcitrance of psychology to phrenology, the resistance of astronomy to astrology and the scepticism of political materialists to phenomenology are warning signs for us here in a long-established field that would appear to have welcoming subjects when it is in fact dealing sometimes summarily with precarious objects.

Perhaps in response to this resistance to this economy of production and audience affects performance studies always, from its earliest days in $4000 \mathrm{BC}$, figured events as privileged at the point at which they confounded this apparent distancing. More recently, in what we might refer to as 'the long ceramic age', the attraction of anthropology and psychoanalytic theory, two modes of understanding that value embeddedness, participation and the allegorical interpretation of the hidden or repressed, is indicative of this urge for proximity. At least these hermeneutics announce an engagement with the 'less fake' if not the real.

Performance studies' interest in processes as contrasting as legal practices and ritual ceremonial, indeed my own interest in the anthropological machine, the architectural construction of speech sites and the performativity of the Freudian 'talking 
cure', share an investment in their volumetric quality, the rounded quality that can appear to be entered into, the promise of interactivity fulfilled (Read, 1993 $\&$ 2008). There is a sense in which performance studies have always wanted to join in, not to look on. Hence the recalcitrant, bloody headed (if not minded) obduracy of Tino Sehgal's ICA floor piece to performance thought. Performance has assiduously cultivated the terminology of participant observation and therapeutic dialogue to imply the interactive quality of this practice.

This emphasis is fine as long as it is not mistaken for politics. It is simply the participatory rhetorical ambience of a discipline that developed over several thousand years in tension with the dominant mode of distanced aesthetic seeing and reading (scanning) that preceded it at the outset of the ceramic age. And while it has a welcome affirmative aspect, a collaborative social feel, it requires a synthetic conflict theory to act upon to do its work. To give its work a sense of dramatic tension beyond the obvious observation that with a floor that dense there is enough resistance to go around.

Any performance studies worth its salt would, in my view, have to account not only for its common subjects (identified historically and with an eye to victim-status by race, class and identity), but in the spirit of the democratic materialism developed in these preparatory notes begin to think through and practice the conditioning grounds of these inequalities. Subjects cannot in and of themselves tell us very much about the relations of production that gave rise to them. That the theatre has acted as the last human venue for these explorations should not privilege it in the order of performance's other, eclectic extra-theatrical interests (including the media interests of those at EVA). But neither should it deny the concrete stage its due weight given that this volume is simply the denser 1970s version of what has traditionally been figured as hollow and somehow incapacitated by the demands of performance's reals. The physicality of performance here does not refer to the old binary of body and mind, practising artist and thinking observer, but rather the precise material conditions within which all performance does its work.

The ceramic age within which the rhetorics of performance still operates, an apparently observable surface with the promise of an interactivity somewhere behind, is not a metaphor but a physical condition which performance thinking still has to get to grips with if only to feel the slipperiness of its alluring, apparently permanent permeability. That this 'age' to all intents and purposes ended with the invention of photography simply marks out performance's peculiar appetite for anachronistic behaviour, conduct which is going to look increasingly peculiar as the century long 'age of the apparatus' begins to be recognised as the dominant paradigm of our times. It is a peculiarity performance might wish to cultivate as its most cherished asset.

\section{THE AGE OF THE APPARATUS: PREPARATION FOR PRACTICE}

For notes and diagrams that arise from the 'live' paper: 


\section{REFERENCES}

Auslander, P. (1997) Liveness. Routledge, London.

Bataille, G. (2005) The Cradle of Humanity. Trans. by Kendall, M. \& Kendall, S. Zone Books, New York.

Bourriaud, N. (2002) Relational Aesthetics. Trans. by Pleasance, S \& Fronza Woods, F. Les Presses du reel, Dijon. p. 36.

Flusser V. (2000), Towards a Philosophy of Photography. Reaktion, London. p. 25.

Pearson, M. \& Michael Shanks, M. (2000)

Theatre/Archeology. Routledge, London.

Read, A. (1993) Theatre \& Everyday Life: An Ethics of Performance. Routledge, London.

Read, A. (2008) Theatre, Intimacy \& Engagement: The Last Human Venue. Palgrave, Houndmills.

Tanizaki, J. (2001) In Praise of Shadows, London: Vintage, London, 2001. pp. 19-20.

\begin{abstract}
'By opening a passage on something called the 'Stone Age' in the ICA in 2007 I want to alert the reader from the outset to the coeval possibility that defines a simultaneous rather than a consequential pattern to the various 'ages' I am noting here. In this way the 'stone age' operates as a paradigm rather than historically specific moment equally describing contemporary and ancient practices. The same could be said for the ceramic age and the age of the apparatus, indeed my argument precisely rests on the assumption that the model of the ceramic age still defines certain theatrical practices in 2010 and is likely to do so for as long as the fourth wall retains its marvellous lustre despite all signs to the interactive contrary. If this strikes the reader as being loose with the chronology of age then a brief pause to consider what lies beneath our feet will reassure as to the potential of a complex, coeval ground.

"Erika Fische Lichte suggests that this legacy is the legacy of the $20^{\text {th }}$ century theatre.
\end{abstract}

